\title{
Relationship between the Electronic Structure and Acidic-Basic Properties of 4-Substituted Pyridine N-Oxides
}

\author{
Lech Chmurzyński*, Adam Liwo, and Anna Tempczyk \\ Institute of Chemistry, University of Gdańsk, ul. Sobieskiego 18, 80952 Gdańsk, Poland \\ Z. Naturforsch. 44b, 1263-1270 (1989); received June 2, 1989 \\ 4-Substituted Pyridine N-Oxides, Electronic Properties, Protonation Energy, \\ $\mathrm{CNDO} / 2$ and $\mathrm{MNDO}$, Correlation with $\mathrm{pK}_{a}$ \\ $\mathrm{CNDO} / 2$ and MNDO calculations on pyridine N-oxide (PyO), 4-nitro- (4 $\left.\mathrm{NO}_{2} \mathrm{PyO}\right)$, 4-methyl- \\ (4 PicO), 4-methoxy- (4 MeOPyO), and 4- $\mathrm{N}^{\prime}, \mathrm{N}^{\prime}$-dimethylamine-pyridine N-oxide \\ $\left(4 \mathrm{~N}^{\prime}, \mathrm{N}^{\prime} \mathrm{Me}{ }_{2} \mathrm{PyO}\right)$ and on their protonated forms have been carried out. Unknown geometries \\ have been obtained by optimization of the MNDO energy. It has been shown that for $4 \mathrm{NO}_{2} \mathrm{PyO}$, \\ $4 \mathrm{MeOPyO}$, and $4 \mathrm{~N}^{\prime}, \mathrm{N}^{\prime} \mathrm{Me}_{2} \mathrm{PyO} \mathrm{N}$-oxide oxygen protonated forms are much more energetically \\ stable than the forms protonated on substituents. The calculated ionization potentials and dipole \\ moments of the compounds studied are in good agreement with the experimental data. Both \\ $\mathrm{CNDO} / 2$ and MNDO protonation energies correlate well with the experimental $\mathrm{pK}_{a}$ values deter- \\ mined in four different solvents: acetonitrile, propylene carbonate, nitromethane, and water, the \\ slopes being however much less than unity which indicates the important role of the solvation \\ effect. Based on the parameters of the correlations obtained the protolytic and solvation proper- \\ ties of the solvents studied have been discussed.
}

\section{Introduction}

Heterocyclic amine $\mathrm{N}$-oxides are compounds of interest, owing to their biological activity [1]. Relatively few aromatic $\mathrm{N}$-oxides occur in nature, but a large number of them have been synthesized and tested for biological activity. No well-defined mechanism of this kind of activity has emerged, though suggestions have been advanced that the primary reaction may involve modification of enzymes or biological redox systems and/or alteration of the nucleic acids [2-4]. Therefore pyridine $\mathrm{N}$-oxide and its derivatives are particularly interesting from the point of view of structure and physicochemical properties.

The molecular structures of pyridine $\mathrm{N}$-oxide and some of its derivatives have been determined [5-9]. The ionization potentials have been measured by the photoelectron spectroscopy [10-11]. The UV spectra have been recorded and discussed [12-18]. Many $\mathrm{N}$-oxides were subjects of numerous theoretical studies from HMO to ab initio level [13, 17-26].

Although there are a great number of publications dealing with the theoretical explanation of various chemical and spectral properties of $\mathrm{N}$-oxides themselves, relatively few papers refer to theoretical

\footnotetext{
* Reprint requests to Dr. L. Chmurzyński.

Verlag der Zeitschrift für Naturforschung, D-7400 Tübingen 0932-0776/89/1000-1263/\$ 01.00/0
}

studies of acidic-basic properties, as well as hydrogen bonding phenomena of these compounds. We thought it, therefore, wothwhile to carry out a theoretical investigation into the electronic structure of some substituted pyridine $\mathrm{N}$-oxides which exhibit different acidic-basic properties. Moreover, comparing the theoretically obtained protonation energies which relate to the gas phase proton affinities with the acidity constants in various solvents makes possible the solvent role to be estimated. Besides, with the use of the experimental data available, we wanted to prove whether the semiempirical $\mathrm{MO}$ methods customarily applied could reproduce correctly the proton affinities, ionization potentials, and dipole moments of this class of compounds.

\section{Compounds Studied and Methods Applied}

We have chosen pyridine $\mathrm{N}$-oxide and its 4-nitro(4 $\left.\mathrm{NO}_{2} \mathrm{PyO}\right)$, 4-methyl- (4 MePyO), 4-methoxy(4 MeOPyO), and 4- $\mathrm{N}^{\prime}, \mathrm{N}^{\prime}$-dimethylamino-

$\left(4 \mathrm{~N}^{\prime}, \mathrm{N}^{\prime} \mathrm{Me}_{2} \mathrm{PyO}\right)$ derivatives. According to their experimental $\mathrm{pK}_{a}[27-33]$ and $\mathrm{I}_{\mathrm{P}}[10-11]$ values, these compounds exhibit a wide range of acidic-basic and redox properties. The latter three compounds are of particular interest, as they possess two potential centers of protonation.

SCF LCAO MO calculations were carried out with the use of the CNDO/2 method of Pople and Segal [34] and MNDO method of Dewar and Thiel [35]. 
Ionization potentials and electron affinities were calculated according to Koopman's theorem as numbers opposite to the energy of highest occupied MO and the energy of the lowest MO, respectively. To analyse the bond orders we used the $\mathrm{CNDO} / 2$ Wiberg indices [36]. Geometry optimization was carried out by a DFP routine included in the Dewar and Thiel MNDO program [35].

\section{Results and Discussion}

\section{Molecular geometries}

The molecular geometries of $\mathrm{PyO}, \mathrm{PyOH}^{+}$, $4 \mathrm{NO}_{2} \mathrm{PyO}$, and $4 \mathrm{MeOPyO}$ have been taken from refs. [5, 6, 9, 37], respectively. For the rest of the compounds we could not find any reliable experimental data. Therefore we chose the geometric parameters by extrapolating from related compounds or by performing MNDO optimization of some parts of the geometry.

We have found that MNDO gives too short a $\mathrm{N}$-O bond of the N-oxide fragment (e.g. 1.23 $\AA$ for $\mathrm{PyO}$ and $1.29 \AA$ for $\mathrm{Me}_{3} \mathrm{NO}$, while the experimental data are $1.29 \AA$ and $1.388 \AA$, respectively). Therefore for $4 \mathrm{~N}^{\prime}, \mathrm{N}^{\prime} \mathrm{Me}_{2} \mathrm{PyO}$ as well as for its protonated form where no experimental data were available we assumed the geometry of the $\mathrm{N}$-oxide fragment and that of the pyridine ring to be the same as for $\mathrm{PyO}$ and $\mathrm{PyOH}^{+}$, respectively. For $4 \mathrm{MeOPyOH}^{+}$and $4 \mathrm{NO}_{2} \mathrm{PyOH}^{+}$we lengthened the $\mathrm{N}-\mathrm{O}$ bond by $0.08 \AA$ and shortened the $\mathrm{N}-\mathrm{C}$ bonds of the ring by $0.05 \AA$, values which are observed when passing from $\mathrm{PyO}$ to $\mathrm{PyOH}^{+}$. For all compounds studied it was necessary to make some small changes in some of the bond angles of the ring in order to satisfy the ring closure and symmetry conditions.

In all $\mathrm{N}$-oxide oxygen protonated $\mathrm{N}$-oxides we assumed the $\mathrm{O}-\mathrm{H}$ distance of $1.03 \AA$ and $\mathrm{N}-\mathrm{O}-\mathrm{H}$ bond angle of $110^{\circ}$. The first value was found by analysing the $\mathrm{CNDO} / 2$ energy surface of protonated trimethylamine $\mathrm{N}$-oxide, while the second is the value of $\mathrm{Cl} \cdots \mathrm{O}-\mathrm{N}$ angle in crystal trimethylammonium N-oxide chloride [39]. Although MNDO optimization of the $\mathrm{O}-\mathrm{H}$ distance performed for protonated pyridine $\mathrm{N}$-oxide gave a value of $1.0 \AA$, we decided to retain the $\mathrm{CNDO} / 2$-optimal distance, due to a small change in energy during optimization. For all $\mathrm{N}$-oxide protonated forms we assumed a perpendicular position of the proton to the pyridine ring.
For $4 \mathrm{MeOPyO}, 4 \mathrm{~N}^{\prime}, \mathrm{N}^{\prime} \mathrm{Me}_{2} \mathrm{PyO}$, and their protonated forms we optimized some parts of the geometry of the substituents. The results are as follows (see Fig. 1 for atom numbering):

4 MeOPyO: $\mathrm{d}\left(\mathrm{C}^{4}-\mathrm{O}\right)=1.361 \AA, \alpha\left(\mathrm{C}^{4}-\mathrm{O}-\mathrm{C}\right)=$ $109.34^{\circ}$.

$\mathrm{N}$-oxide oxygen protonated $4 \mathrm{MeOPyO}:\left(\mathrm{C}^{4}-\mathrm{O}\right)=$ $1.351 \AA, \alpha\left(\mathrm{C}^{4}-\mathrm{O}-\mathrm{C}\right)=123.33^{\circ}$.

Methoxy oxygen protonated $4 \mathrm{MeOPyO}$ : $\mathrm{d}\left(\mathrm{C}^{4}-\mathrm{O}\right)=1.406 \AA, \alpha\left(\mathrm{C}^{4}-\mathrm{O}-\mathrm{C}\right)=124.33^{\circ}$, $\beta\left(\mathrm{C}-\mathrm{O}-\mathrm{C}^{4}-\mathrm{C}^{3}\right)=109.9^{\circ} ; \mathrm{d}(\mathrm{O}-\mathrm{H})=1.01 \AA$, $\alpha\left(\mathrm{C}^{4}-\mathrm{O}-\mathrm{H}\right)=109.5^{\circ}, \beta\left(\mathrm{H}-\mathrm{O}-\mathrm{C}^{4}-\mathrm{C}^{6}\right)=-144.9^{\circ}$. $\left.4 \mathrm{~N}^{\prime}, \mathrm{N}^{\prime} \mathrm{Me}_{2} \mathrm{PyO}\right): \mathrm{d}\left(\mathrm{C}^{4}-\mathrm{N}\right)=1.409 \AA$, $\alpha\left(\mathrm{C}^{4}-\mathrm{N}-\mathrm{C}^{\mathrm{I}}\right)=\alpha\left(\mathrm{C}^{4}-\mathrm{N}-\mathrm{C}^{\mathrm{II}}\right)=121.4^{\circ}$, $\beta\left(\mathrm{C}^{\mathrm{I}}-\mathrm{N}-\mathrm{C}^{4}-\mathrm{C}^{3}\right)=-\beta\left(\mathrm{C}^{\mathrm{I}}-\mathrm{N}-\mathrm{C}^{4}-\mathrm{C}^{5}\right)=2.9^{\circ}$.

$\mathrm{N}$-oxide oxygen protonated $4 \mathrm{~N}^{\prime}, \mathrm{N}^{\prime} \mathrm{Me}_{2} \mathrm{PyO}$ : $\mathrm{d}\left(\mathrm{C}^{4}-\mathrm{N}\right)=1.393 \AA, \alpha\left(\mathrm{C}^{4}-\mathrm{N}-\mathrm{C}^{\mathrm{I}}\right)=\alpha\left(\mathrm{C}^{4}-\mathrm{N}-\mathrm{C}^{\mathrm{II}}\right)=$ $121.75^{\circ}, \beta\left(\mathrm{C}^{\mathrm{I}}-\mathrm{N}-\mathrm{C}^{4}-\mathrm{C}^{3}\right)=-\beta\left(\mathrm{C}^{\mathrm{I}}-\mathrm{N}-\mathrm{C}^{4}-\mathrm{C}^{5}\right)=$ $0.9^{\circ}$.

Amine nitrogen protonated $4 \mathrm{~N}^{\prime}, \mathrm{N}^{\prime} \mathrm{Me}_{2} \mathrm{PyO}$ : $\mathrm{d}\left(\mathrm{C}^{4}-\mathrm{N}\right)=1.499 \AA, \alpha\left(\mathrm{C}^{4}-\mathrm{N}-\mathrm{C}^{\mathrm{I}}\right)=\alpha\left(\mathrm{C}^{4}-\mathrm{N}-\mathrm{C}^{\mathrm{II}}\right)=$ $113.28^{\circ}, \beta\left(\mathrm{C}^{\mathrm{I}}-\mathrm{N}-\mathrm{C}^{4}-\mathrm{C}^{3}\right)=-\beta\left(\mathrm{C}^{\mathrm{I}}-\mathrm{N}-\mathrm{C}^{4}-\mathrm{C}^{5}\right)=$ $-25.4^{\circ} ; \mathrm{d}(\mathrm{N}-\mathrm{H})=1.021 \AA, \alpha\left(\mathrm{C}^{4}-\mathrm{N}-\mathrm{H}\right)=104.28^{\circ}$, $\beta\left(\mathrm{H}-\mathrm{N}-\mathrm{C}^{4}-\mathrm{C}^{3}\right)=90^{\circ}$.

For all forms of $4 \mathrm{MeOPyO}$ we assumed $\mathrm{d}(\mathrm{C}-\mathrm{O})=$ $1.43 \AA$ and $\alpha(\mathrm{O}-\mathrm{C}-\mathrm{H})=109.5^{\circ}$. For $4 \mathrm{MeOPyO}$ and $4 \mathrm{MeOPyOH}^{+}$we assumed a perpendicular position of the methoxy group to the ring. For all forms of $4 \mathrm{~N}^{\prime}, \mathrm{N}^{\prime} \mathrm{Me}_{2} \mathrm{PyO}$ we assumed $\mathrm{d}\left(\mathrm{N}-\mathrm{C}^{\mathrm{I}}\right)=$ $\mathrm{d}\left(\mathrm{N}-\mathrm{C}^{\mathrm{II}}\right)=1.472 \AA$, all $\mathrm{d}\left(\mathrm{C}^{\mathrm{I}}-\mathrm{H}\right)=\mathrm{d}\left(\mathrm{C}^{\mathrm{II}}-\mathrm{H}\right)=$ $1.1 \AA$, and all $\alpha\left(\mathrm{N}-\mathrm{C}^{\mathrm{I}}-\mathrm{H}\right)$ and $\alpha\left(\mathrm{N}-\mathrm{C}^{\mathrm{II}}-\mathrm{H}\right)=$ $109.5^{\circ}$.

\section{Electronic properties - \\ comparison with the experimental data}

The protonation energies obtained by $\mathrm{CNDO} / 2$ and MNDO methods are summarized in Table I. For comparison, the $\mathrm{CNDO} / 2$ and MNDO protonation energy of trimethylamine N-oxide (the simplest aliphatic analogue) is $-15.62 \mathrm{eV}$ and $-7.80 \mathrm{eV}$, respectively [32]. This is consistent with the fact that trimethylamine $\mathrm{N}$-oxide is a base of strength comparable with that of the most basic aromatic $\mathrm{N}$-oxides.

As shown, for $4 \mathrm{NO}_{2} \mathrm{PyO}, 4 \mathrm{MeOPyO}$, and $4 \mathrm{~N}^{\prime}, \mathrm{N}^{\prime} \mathrm{Me}_{2} \mathrm{PyO}$ the protonation of $\mathrm{N}$-oxide oxygen is much more favourable than the protonation of substituents. It can therefore be concluded that the corresponding cationic acids exist as $\mathrm{N}$-oxide oxygen protonated forms. 
1. a)

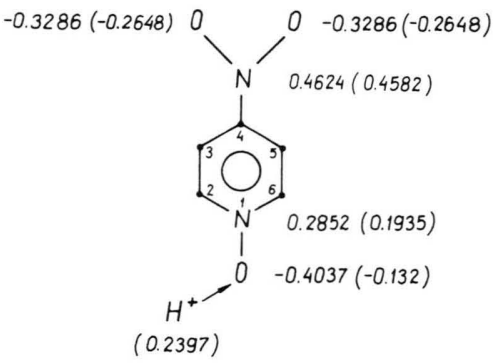

2.

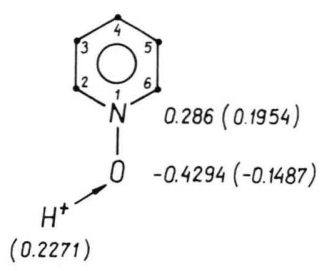

4. a)<smiles></smiles>

5. a)

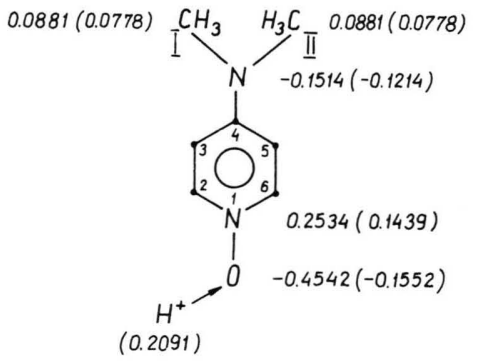

b)

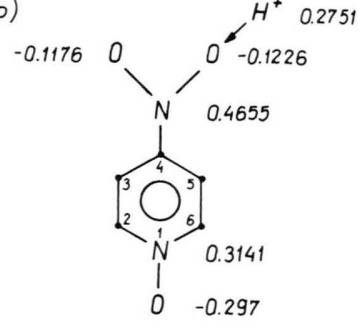

3.<smiles></smiles>

b)<smiles></smiles>

b)

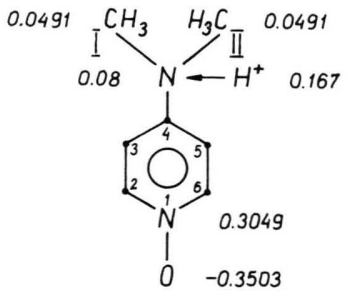

Fig. 1. Structures and some selected $\mathrm{CNDO} / 2$ charges of $\mathrm{N}$-oxides $\left(1-4 \mathrm{NO}_{2} \mathrm{PyO}, 2-\mathrm{PyO}, 3-4 \mathrm{PicO}\right.$, 4 - $\left.4 \mathrm{MeOPyO}, 5-4 \mathrm{~N}^{\prime}, \mathrm{N}^{\prime} \mathrm{Me}_{2} \mathrm{PyO}\right)$ and their protonated forms. Parts a) of pictures 1,4 , and 5 display charges of free $\mathrm{N}$-oxides and their $\mathrm{N}$-oxide oxygen protonated forms (in brackets), while in parts b) are charges of $\mathrm{N}$-oxides protonated on substituents.

\begin{tabular}{|c|c|c|c|c|c|c|}
\hline \multirow[t]{2}{*}{ Compound } & \multicolumn{2}{|c|}{ Protonation energies $^{\mathrm{a}}[\mathrm{eV}]$} & \multicolumn{4}{|c|}{$\begin{array}{l}\mathrm{pK}_{a} \text { values of the proton- } \\
\text { ated forms }\end{array}$} \\
\hline & $\mathrm{CNDO} / 2$ & MNDO & $\mathrm{H}_{2} \mathrm{O}$ & $\mathrm{AN}^{\mathrm{f}}$ & $\mathrm{PC}^{\mathrm{g}}$ & $\mathrm{NM}^{\mathrm{h}}$ \\
\hline $4 \mathrm{NO}_{2} \mathrm{PyO}$ & $-14.06[-13.61]$ & $-6.76[-6.02]$ & $1.7^{\mathrm{b}}$ & 5.69 & 4.71 & 4.51 \\
\hline $\mathrm{PyO}$ & -15.35 & -7.81 & $0.79^{c}$ & 10.02 & 8.55 & 8.75 \\
\hline $4 \mathrm{MePyO}$ & -15.54 & -8.16 & $1.29^{c}$ & 11.00 & 9.91 & 9.76 \\
\hline $4 \mathrm{MeOpyO}$ & $-1556[-1206]$ & $-7.82[-5.61]$ & $2.04^{\mathrm{d}}$ & 12.28 & 10.89 & - \\
\hline $4 \mathrm{~N}^{\prime} \mathrm{N}^{\prime} \mathrm{Me}_{2} \mathrm{PyO}$ & $-15.72[-13.52]$ & $-8.31[-6.23]$ & $3.88^{\mathrm{e}}$ & 15.63 & 12.83 & - \\
\hline
\end{tabular}

Table I. CNDO $/ 2$ and MNDO protonation energies of the $\mathrm{N}$-oxides studied and $\mathrm{pK}_{a}$ values of their protonated forms.

a The energies corresponding to protonation on substituents are in brackets; ${ }^{\mathrm{b}}$ ref. [27]; ${ }^{\mathrm{c}}$ ref. [28]; ${ }^{\mathrm{d}}$ ref. [29]; ${ }^{\mathrm{e}}$ ref. [30]; ${ }^{\mathrm{f}}$ acetonitrile, values from ref. [31];

${ }^{\mathrm{g}}$ propylene carbonate, values from ref. [32]; ${ }^{\mathrm{h}}$ nitromethane, values from ref. [33]. 
The protonation energies of the compounds studied are generally in the order which can be predicted on the basis of the substituent effect. This is better satisfied by the $\mathrm{CNDO} / 2$ values. Moreover, both $\mathrm{CNDO} / 2$ and MNDO protonation energies approximately follow the order of the $-\mathrm{pK}_{a}$ values determined in some aprotic solvents and in water, the order of the $\mathrm{CNDO} / 2$ values being even exactly the same (see Table I). Using the well-known relation $\Delta \mathrm{G}=-\mathrm{RT} \ln \mathrm{K}$ we have calculated the $\Delta \mathrm{G}$ 's of protonation for four solvents of different protolytic properties and polarity: acetonitrile ( $\mathrm{pK}_{a}$ values from Ref. [31]), propylene carbonate ( $\mathrm{pK}_{a}$ values from Ref. [32]), nitromethane $\left(\mathrm{pK}_{a}\right.$ values from Ref. [33]), and water ( $\mathrm{pK}_{a}$ values from Refs. [27-30]). These values have been correlated both with the $\mathrm{CNDO} / 2$ and MNDO protonation energies. The coefficients in the equation $-\Delta \mathrm{G}_{\text {prot }}^{(\mathrm{s})}=\mathrm{a}\left(-\Delta \mathrm{E}_{\text {prot }}\right)+\mathrm{b}$ and the correlation coefficients are summarized in Table II, the sample plots for acetonitrile being shown in Fig. 2 and 3 .

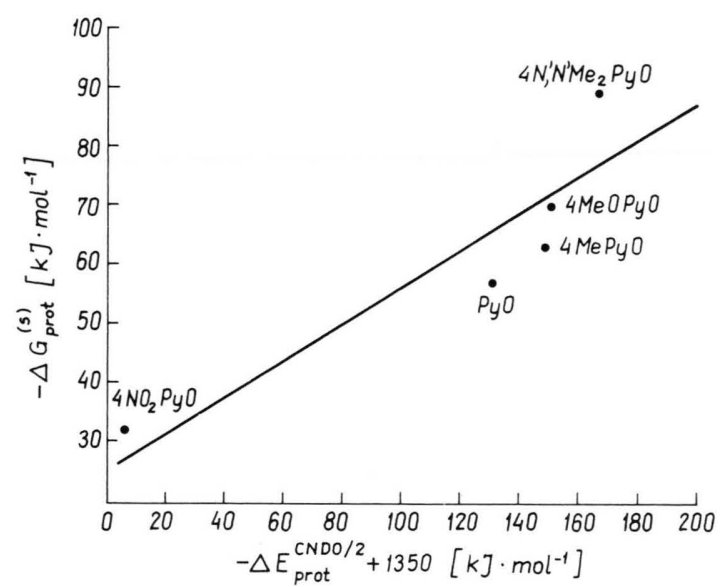

Fig. 2. Correlation between $\mathrm{CNDO} / 2$ protonation energies of $\mathrm{N}$-oxides and their experimental $-\Delta \mathrm{G}$ of protonation.

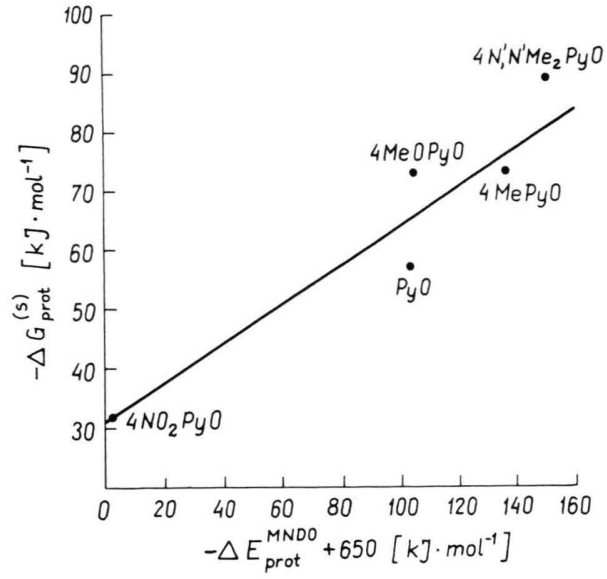

Fig. 3. Correlation between MNDO protonation energies of $\mathrm{N}$-oxides and their experimental $-\Delta \mathrm{G}$ of protonation.

It can be observed that the correlation is good for both $\mathrm{CNDO} / 2$ and MNDO values, except the case of water. Based on the low values of the correlation coefficients in the latter case it can be concluded that the $\mathrm{pK}_{a}$ values depend very weakly on the protonation energy. This is also justified by the fact that slopes of different sign are obtained when taking either $\mathrm{CNDO} / 2$ or MNDO values and that the values of the slopes are of the same order as their standard deviations.

For solvents other than water we can observe that the slopes obtained on the basis of either $\mathrm{CNDO} / 2$ or MNDO values are within the standard deviation the same for both correlations. It can therefore be supposed that both $\mathrm{CNDO} / 2$ and MNDO reproduce well the relations between the protonation energies for this class of compounds. The intercepts differ largely, which is understandable having borne in mind that $\mathrm{CNDO} / 2$ always gives far too large values of the

\begin{tabular}{|c|c|c|c|c|}
\hline Parameter $^{\mathrm{a}}$ & $\begin{array}{l}\text { Solvent }{ }^{\mathrm{b}} \\
\text { AN }\end{array}$ & $\mathrm{PC}$ & NM & water \\
\hline $\mathrm{a}$ & $\begin{array}{l}0.289(0.081) \\
0.323(0.090)\end{array}$ & $\begin{array}{l}0.254(0.054) \\
0.279(0.065)\end{array}$ & $\begin{array}{l}0.207(0.013) \\
0.229(0.014)\end{array}$ & $\begin{array}{r}0.030(0.058) \\
-0.068(0.031)\end{array}$ \\
\hline $\mathrm{b}$ & $\begin{array}{l}-356(117) \\
-176(66)\end{array}$ & $\begin{array}{l}-314(78) \\
-152(48)\end{array}$ & $\begin{array}{l}-251(19) \\
-121(10)\end{array}$ & $\begin{array}{r}-33(84) \\
58(21)\end{array}$ \\
\hline $\mathrm{r}^{\mathrm{c}}$ & $\begin{array}{l}0.9003 \\
0.9012\end{array}$ & $\begin{array}{l}0.9391 \\
0.9271\end{array}$ & $\begin{array}{l}0.9980 \\
0.9982\end{array}$ & $\begin{array}{l}0.2898 \\
0.7847\end{array}$ \\
\hline
\end{tabular}

\footnotetext{
${ }^{a}$ Upper values correspond to the correlation of CNDO/2, lower to MNDO correlation; ${ }^{b}$ see Table I for abbreviations of the solvents names; ${ }^{c} \mathrm{r}$ is the linear regression correlation coefficient.
}

Table II. Values of a and b coefficients in equation $-\Delta \mathrm{G}^{(\mathrm{s})}{ }_{\text {prot }}=$ $\mathrm{a}\left(-\Delta \mathrm{E}_{\mathrm{prot}}\right)+\mathrm{b}$ obtained for the solvents under consideration. 


\begin{tabular}{|c|c|c|c|c|c|}
\hline \multirow[t]{2}{*}{ Species } & \multicolumn{3}{|c|}{ Ionization potential $[\mathrm{eV}]$} & \multicolumn{2}{|c|}{ Electron affinity $[\mathrm{eV}$} \\
\hline & Obs. & $\mathrm{CNDO} / 2$ & MNDO & $\mathrm{CNDO} / 2$ & MNDO \\
\hline $4 \mathrm{NO}_{2} \mathrm{PyO}$ & $9.03^{\mathrm{a}}$ & 11.63 & 9.83 & 0.13 & -2.16 \\
\hline $\mathrm{PyO}$ & $\begin{array}{l}8.38^{\mathrm{a}} \\
8.46^{\mathrm{b}}\end{array}$ & 10.63 & 8.86 & 2.17 & -0.16 \\
\hline $4 \mathrm{MePyO}$ & $\begin{array}{l}8.12^{\mathrm{a}} \\
8.17^{\mathrm{b}}\end{array}$ & 10.79 & 8.73 & 2.05 & -0.82 \\
\hline $4 \mathrm{MeOPyO}$ & $\begin{array}{l}7.74^{\mathrm{a}} \\
7.89^{\mathrm{b}}\end{array}$ & 10.20 & 8.82 & 2.24 & -0.77 \\
\hline $4 \mathrm{~N}^{\prime} \mathrm{N}^{\prime} \mathrm{Me}_{2} \mathrm{PyO}$ & $7.21^{\mathrm{a}}$ & 9.53 & 8.16 & 2.57 & -0.37 \\
\hline
\end{tabular}

Table III. Ionization potentials and electron affinities of N-oxides studied.

${ }^{a}$ Ref. [10]; ${ }^{b}$ ref. [11].

protonation energies, although it represents well, in general, the relations between them.

The next step of our study was to examine the capability of the semiempirical methods to reproduce the redox properties of $\mathrm{N}$-oxides studied. Such properties are e.g. connected directly with the antifungal activity of these compounds. We have compared the $\mathrm{CNDO} / 2$ and MNDO ionization potentials to the experimental data available. The results are in Table III. Both methods gave the order of ionization potentials observed experimentally. The MNDO values are close to experiment, while the potentials obtained by the $\mathrm{CNDO} / 2$ method are of several electronvolts higher. The MNDO values agree well with those obtained by Kulkarni et al. by IEH and $\mathrm{MINDO} / 2$ [24].

Owing to the good agreement of the calculated and experimental ionization potentials we can suppose that the electron affinities are also reproduced correctly. The $\mathrm{CNDO} / 2$ and $\mathrm{MNDO}$ values are shown in Table III. Although there is some disagreement between them, as MNDO shows energy gain and $\mathrm{CNDO} / 2$ energy loss on binding the additional electron, in either case the values are in the same order which, moreover, is consistent with the substituent effect. From our calculations we can conclude that all $\mathrm{N}$-oxides under are very effective oxidizers, the strongest one being $4 \mathrm{NO}_{2} \mathrm{PyO}$, and the weakest $4 \mathrm{~N}^{\prime}, \mathrm{N}^{\prime} \mathrm{Me}_{2} \mathrm{PyO}$.

In order to obtain one more confirmation of the capability of semiempirical MO methods to deal with $\mathrm{N}$-oxides, we have compared the $\mathrm{CNDO} / 2$ and MNDO dipole moments with the experimental data available (see Table IV). The calculated values are very similar and agree well with the experiment. Moreover, the agreement is better than in the case of

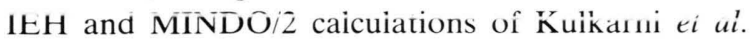
[24].
Table IV. Comparison of theoretical and experimental values of the dipole moments of $\mathrm{N}$-oxides studied.

\begin{tabular}{|c|c|c|c|}
\hline \multirow[t]{2}{*}{ Compound } & \multicolumn{3}{|c|}{ Dipole moment [D] } \\
\hline & Obs. & $\mathrm{CNDO} / 2$ & MNDO \\
\hline $4 \mathrm{NO}_{2} \mathrm{PyO}$ & $0.71^{\mathrm{a}}$ & 0.62 & 0.93 \\
\hline $\mathrm{PyO}$ & $4.24^{b}$ & 4.54 & 4.51 \\
\hline $4 \mathrm{MePyO}$ & $4.74^{\mathrm{a}}$ & 5.60 & 5.19 \\
\hline $4 \mathrm{MeOPyO}$ & $5.08^{\mathrm{c}}$ & 4.53 & 4.39 \\
\hline $4 \mathrm{~N}^{\prime} \mathrm{N}^{\prime} \mathrm{Me}_{2} \mathrm{PyO}$ & $6.76^{c}$ & 5.91 & 6.40 \\
\hline
\end{tabular}

${ }^{\mathrm{a}}$ Ref. [19]; ${ }^{\mathrm{b}}$ ref. [1]; ${ }^{\mathrm{c}}$ ref. [40].

\section{The relationship between the acidic-basic and electronic properties of $\mathrm{N}$-oxides}

As can be inferred from the data in Tables I-III and Fig. 1, all the electronic quantities vary in the same direction. In particular, on increasing (in its absolute value) the net charge of the N-oxide oxygen the protonation energy increases in its absolute value, while the ionization potential decreases. This regularity is a direct consequence of the fact that these properties affect mainly the $\mathrm{N}$-oxide oxygen. Based on the values of the Wiberg indices of $\mathrm{N}$-oxides and their protonated forms (see Table $\mathrm{V}$ ) we can note that the $\mathrm{N}-\mathrm{O}$ bond order in a free $\mathrm{N}$-oxide is only slightly greater than one and decreases, thus, only very slightly on protonation. It can therefore be concluded that protonation has no significant effect on the electronic structure of the ring. Further, from the HOMO coefficients we can gather that the electronic density of oxygen is mainly affected on ionization. To enable deeper conclusions to be drawn we have correlated the $\mathrm{CNDO} / 2 \mathrm{D}$ net oxygen charges (shown in Fig. 1) with the $\mathrm{CNDO} / 2$ protonation energies and ionization potentials, as well as with the experimental ionization potentials. For the proiondiivn energy we have obtained the equation $\Delta \mathrm{E}_{\mathrm{P}}=(33.5 \pm 5.5) \mathrm{q}_{\mathrm{o}}-(0.7 \pm 2.4)$ with the cor- 
relation coefficient of 0.9612 . In the case of the $\mathrm{CNDO} / 2$ and experimental ionization potential the equations are $\mathrm{I}_{\mathrm{P}}=(37.1 \pm 9.1) \mathrm{q}_{\mathrm{O}}+(26.7 \pm 4.0)$ with the correlation coefficient of 0.9202 , and $\mathrm{I}_{\mathrm{P}}=$ $(33.7 \pm 6.2) \mathrm{qo}_{\mathrm{O}}+(22.7 \pm 2.7)$, with the correlation coefficient of 0.9519 , respectively.

In the correlations the values of $E_{P}$ and $I_{P}$ are in electronvolts, while the charge in the electronic charge unit. We can observe that in the case of the protonation energy the slope and in the case of ionization potential both slope and intercept are very similar the energy conversion factor from atomic units into electronvolts (27.21). This means that not only both processes affect mainly the oxygen, but also that their nature is mainly electrostatic. In fact, if they were purely electrostatic, the protonation energy would consist mainly of the energy of electrostatic interaction of the proton carrying a unity positive charge, and the negatively charged $\mathrm{N}$-oxide oxygen (we can neglect, by the time, its interaction with other atoms which are less charged and more far than the oxygen) and should be thus proportional to the oxygen net charge. From the low value of the intercept which is, moreover, lower than its standard deviation, we can infer that this proportionality, with the appropriate coefficient, holds in our correlation. The ionization potential is in the case of net oxygen charge equal to zero simply the energy of separation of two unity charges of the opposite signs which, within the confidence interval, agrees with the value of intercept in our correlations. Obviously, as the whole $\mathrm{N}$-oxide molecule is neutral, an energy greater than zero is required for ionization, even when the oxygen carries the net unity negative charge, and therefore the slopes in our correlations are greater than the energy conversion factor.

Table V. CNDO/2 Wiberg indices of some bonds of the $\mathrm{N}$-oxides studied and their protonated forms.

\begin{tabular}{llll}
\hline Species & $\mathrm{C}-\mathrm{N}$ bond & $\mathrm{N}-\mathrm{O}$ bond & $\mathrm{O}-\mathrm{H}$ bond \\
\hline $4 \mathrm{NO}_{2} \mathrm{PyO}$ & 1.28 & 1.11 & - \\
$\mathrm{PyO}$ & 1.28 & 1.12 & - \\
$4 \mathrm{MePyO}$ & 1.33 & 0.91 & - \\
$4 \mathrm{MeOPyO}$ & 1.29 & 1.09 & - \\
$4 \mathrm{~N}^{\prime} \mathrm{N}^{\prime} \mathrm{Me}_{2} \mathrm{PyO}$ & 1.30 & 1.07 & - \\
$4 \mathrm{NO}_{2} \mathrm{PyOH}^{+}$ & 1.32 & 0.98 & 0.93 \\
$\mathrm{PyOH}^{+}$ & 1.33 & 0.99 & 0.93 \\
$4 \mathrm{MePyOH}^{+}$ & 1.29 & 0.97 & 0.94 \\
$4 \mathrm{MeOPyOH}^{+}$ & 1.31 & 0.98 & 0.94 \\
$4 \mathrm{~N}^{\prime} \mathrm{N}^{\prime} \mathrm{Me}_{2} \mathrm{PyOH}^{+}$ & 1.28 & 0.98 & 0.94 \\
\hline
\end{tabular}

Taking into account the same electrostatic mechanism of all the processes which are connected with the change of electronic properties, we can ask if there is any relationship between the acidic-basic properties of the N-oxides studied in different solvents. We can immediately note that the intercepts and slopes of the correlations between the protonation energy and experimental $\Delta \mathrm{G}$ of protonation in solution exhibit striking regularity for both $\mathrm{CNDO} / 2$ and $\mathrm{MNDO}$ values: the greater the slope, the greater the intercept in its absolute value. We have therefore performed correlation between the intercepts and slopes for all the solvents considered. The plots for both $\mathrm{CNDO} / 2$ and MNDO are shown in Figs 4 and 5. The equations are $\mathrm{a}=(0.7983 \pm 0.0074) \times 10^{-2} \mathrm{~b}+(4.5 \pm 2.0)$ with the correlation coefficient of 0.9999 and

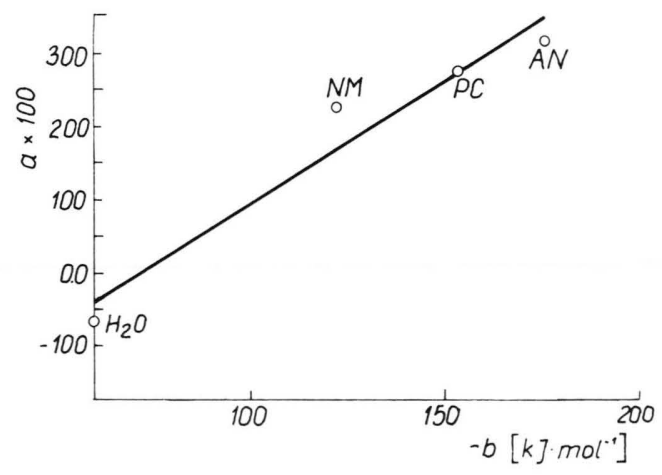

Fig. 4. Correlation between the intercepts (b) and slopes (a) of the plots of experimental $\Delta \mathrm{G}$ of protonation $v s$. the theoretical $\mathrm{CNDO} / 2$ protonation energies obtained for the solvents studied.

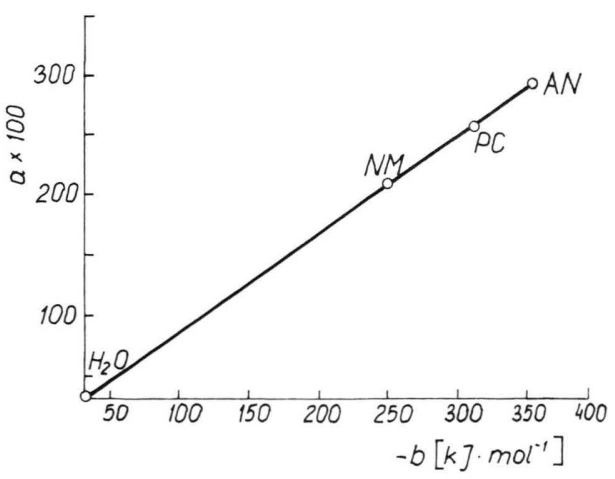

Fig. 5. Correlation between the intercepts (b) and slopes (a) of the plots of experimental $\Delta \mathrm{G}$ of protonation $v s$. the theoretical MNDO energies obtained for the solvents studied. 
$\mathrm{a}=3.37 \pm 0.58) \times 10^{-2} \mathrm{~b}-(2.37 \pm 0.78)$ with the correlation coefficient of 0.9717 for the $\mathrm{CNDO} / 2$ and MNDO method, respectively. The correlation is thus good in both cases and for CNDO/2 even excellent.

The observed regularity can be explained in terms of the energetic effects of the processes occurring during the proton transfer from the solvated cationic acid conjugated to $\mathrm{N}$-oxide to solvent. The energy of this process can be expressed as follows:

$\left.\Delta \mathrm{E}_{\mathrm{PT}}=-\Delta \mathrm{E}_{\text {prot }}+\left(\Delta \mathrm{E}_{\text {solv } \mathrm{H}^{+}}-\Delta \mathrm{E}_{\text {solv BH}}\right)^{+}\right)+\Delta \mathrm{E}_{\text {solv } \mathrm{B}}$ where $\Delta \mathrm{E}_{\mathrm{PT}}$ is the energy of proton transfer from protonated $\mathrm{N}$-oxide to solvent (its value is opposite to the protonation energy in solution), $\mathrm{B}$ and $\mathrm{BH}^{+}$ denote $\mathrm{N}$-oxide and protonated $\mathrm{N}$-oxide, respectively, $\Delta \mathrm{E}_{\text {prot }}$ is the $\mathrm{N}$-oxide protonation energy in the gas phase, $\Delta \mathrm{E}_{\text {solv } \mathrm{X}}$ is the solvation energy of species $\mathrm{X}$.

If the entropy effect is neglected, $\Delta \mathrm{E}_{\mathrm{PT}}$ is just proportional to the $\mathrm{pK}_{a}$ value in the solvent considered. Let $\mathrm{f}_{\mathrm{Nox}}$ describe a certain electronic property of $\mathrm{N}$ oxide (the oxygen net charge, protonation energy, dipole moment, etc.) and $\mathrm{g}_{\text {solv }}$ the "solvation power" of the solvent. If all the energies in the expression above are mainly electrostatic, we can safely assume that $\Delta \mathrm{E}_{\text {prot }}$ should be roughly proportional to $\mathrm{f}_{\mathrm{Nox}}$. Other energies depend either on $g_{\text {solv }}$ or on both $f_{\text {Nox }}$ and $g_{\text {solv }}$. Taking only the solvents of at least medium polarity we can expand these energies in the power series of $f_{\text {Nox }}$ and $g_{\text {solv }}$ and consider the lower order terms in these expansions. From the physical point of view it is reasonable to assume that apart from a constant term a contribution proportional to both $\mathrm{f}_{\mathrm{Nox}}$ and $\mathrm{g}_{\text {solv }}$ is the first significant term in the power series expansion of $\Delta \mathrm{E}_{\text {solv B }}$. Obviously, $\Delta \mathrm{E}_{\text {solv } \mathrm{H}^{+}}$depends only on $\mathrm{g}_{\text {solv }}$ and we can neglect all the terms higher than linear, while in the case of $\Delta \mathrm{E}_{\text {solv }} \mathrm{BH}^{+}$ apart from a term linear in $\mathrm{g}_{\text {solv }}$ which accounts for the nonspecific solvation of a charged species we should also consider a term proportional to $\mathrm{g}_{\text {solv }}$ and $\mathrm{f}_{\mathrm{Nox}}$ to reflect specific solvation of a particular protonated $\mathrm{N}$-oxide. This can be written as follows:

$$
\begin{array}{ll}
\Delta \mathrm{E}_{\text {prot }} & =-\beta_{1} \mathrm{f}_{\text {Nox }} \\
\Delta \mathrm{E}_{\text {solv } \mathrm{H}^{+}} & =-\alpha_{2}-\beta_{2} \mathrm{~g}_{\text {solv }} \\
\Delta \mathrm{E}_{\text {solv BH }} & =-\alpha_{3}-\beta_{3} \mathrm{~g}_{\text {solv }}-\gamma_{3} \mathrm{f}_{\text {Nox }} \mathrm{g}_{\text {solv }} \\
\Delta \mathrm{E}_{\text {solv B }} & =-\alpha_{4}-\gamma_{4} \mathrm{f}_{\text {Nox }} \mathrm{g}_{\text {solv }}
\end{array}
$$

The signs at the coefficients reflect the energetic effects of these processes. Thus the energy of proton transfer can be written as:

$\Delta \mathrm{E}_{\mathrm{PT}}=\alpha_{3}-\alpha_{4}-\alpha_{2}+\left(\beta_{3}-\beta_{2}\right) \mathrm{g}_{\mathrm{solv}}+\left[\beta_{1}-\left(\gamma_{4}-\gamma_{3}\right) \mathrm{g}_{\mathrm{solv}}\right] \mathrm{f}_{\mathrm{Nox}}$
Thus, for the parameters of the plots of $\Delta \mathrm{E}_{\mathrm{PT}} v s$. $-\Delta \mathrm{E}_{\text {prot }}\left(\beta_{1}=1\right)$ we obtain:

$$
\begin{aligned}
& \mathrm{a}=1-\left(\gamma_{4}-\gamma_{3}\right) \mathrm{g}_{\mathrm{solv}} \\
& \mathrm{b}=-\left(\alpha_{2}+\alpha_{4}-\alpha_{3}\right)+\left(\beta_{3}-\beta_{2}\right) \mathrm{g}_{\text {solv }}
\end{aligned}
$$

which clearly shows that these values computed for various solvents should be related by a linear equation as in our correlations.

Because the slope decreases on increasing the "solvation power" of the solvent, we can conclude that the specific contribution to solvation energy is greater in the case of $\mathrm{N}$-oxide than its conjugated cationic acid $\left(\gamma_{4}>\gamma_{3}\right)$ which is reasonable from the physical point of view. Obviously, in the protic solvents, such as water this difference is the greatest, owing to the formation of more effective hydrogen bonds with unprotonated $\mathrm{N}$-oxide oxygen (the contribution due to the formation of hydrogen bonds with the cationic acid proton is included in the nonspecific term $\left.-\beta_{3} \mathrm{~g}_{\text {solv }}\right)$.

The negative values of the intercept can readily be explained by the great energy of solvation of free proton which involves $\alpha_{2}+\alpha_{4}>\alpha_{3}$. Because b decreases in the absolute value on increasing $\mathrm{g}_{\text {solv }}, \beta_{3}$ must be greater than $\beta_{2}$ which means that the energy of solvation of the protonated $\mathrm{N}$-oxide is more sensitive to increasing $g_{\text {solv }}$ than the energy of solvation of the free proton. This can also be explained based on the properties of the solvents. Proton, having very high ionic potential can be efficiently solvated by any polar molecules, while the purely electrostatic solvation of protonated $\mathrm{N}$-oxide molecule is less effective, due to its greater van der Waals sphere. However, if the solvent molecules possess protons able to form hydrogen bonds with the $\mathrm{N}$-oxide oxygen then, apart from the specific contribution to energy which is included in the term $-\gamma_{3} \mathrm{f}_{\text {Nox }} \mathrm{g}_{\text {solv }}$, the "average" radius of the van der Waals sphere will decrease which will, in turn, increase the ionic potential of the protonated $\mathrm{N}$-oxide. The same, though less pronounced effect of decreasing the van der Waals sphere on increasing the energy of interaction with the solvent molecules can also occur in polar aprotic solvents. On the other hand, this effect will be much less pronounced in the case of proton.

In the case of water both intercept and slope are close to zero which means that in this solvent there is little difference in the energy of hydrated cationic acid and hydirated proton pius hydirated î̀-oxicie. This is consistent with the microscopic picture of 
these two states, because as far as the binding of proton is concerned the $\mathrm{N}$-oxide molecule behaves as the water molecule and can to some extent substitute water in the hydrogen bond network.

For polar aprotic (Parker) solvents we could suppose that the order of the $\mathrm{a}$ and $\mathrm{b}$ coefficients will be consistent with their polarity. This holds for propylene carbonate and acetonitrile. Nitromethane, how- ever, having a little lower polarity than acetonitrile, and fairly lower than propylene carbonate, appears as the first in the series, instead of being at the end. This formal inconsistency can however be explained having borne in mind that nitromethane occurs also in its aci-form which is able to act as a proton donor. Rather than a Parker solvent it should be therefore considered as a partially protic solvent.
[1] E. Ochiai, Aromatic Amine Oxides, Elsevier, Amsterdam (1977).

[2] A. R. Katritzky and J. M. Lagowski, Chemistry of the Heterocyclic N-Oxides, Academic Press, London (1971).

[3] J. S. Paul, R. C. Reynolds, and P. O’E. Montgomery, Nature 215, 749 (1967).

[4] G. P. Brown, Prog. Nucleic Acid Res. Mol. Biol. 8, 209 (1968).

[5] J. F. Chiang, J. Chem. Phys. 61, 1280 (1974).

[6] Y. Wang, R. H. Blessing, F. K. Ross, and P. Coppens, Acta Crystallogr. B 32, 572 (1976).

[7] L. Hoesch, J. H. Bierri, J. P. Declercq, G. Germain, and M. Meersche, Helv. Chim. Acta 64, 905 (1981).

[8] M. Jaskólski, M. Gdaniec, and Z. Kosturkiewicz, Pol. J. Chem. 56, 297 (1982).

[9] J. F. Chiang and J. J. Song, J. Mol. Struct. 96, 151 (1982).

[10] J. P. Maier and J. F. Müller, J. Chem. Soc. Faraday Trans. 2 70, 1991 (1974).

[11] M. A. Weiner and M. Lattman, Tetrahedron Lett. 1974, 1709

[12] M. Ito and N. Hata, Bull. Chem. Soc. Jpn. 28, 260 (1965).

[13] M. T. Yamakawa, T. Kubota, and H. Akazawa, Theoret. Chim. Acta 15, 244 (1969).

[14] K. Seibold, G. Wagniere, and H. Lobhart, Helv. Chim. Acta 52, 789 (1969).

[15] R. M. Hochstrasser and D. A. Wiersma, J. Chem. Phys. 55, 5339 (1971).

[16] H. D. Bist, J. D. Panhar, and J. C. D. Brand, J. Mol. Spectrosc. 59, 435 (1976).

[17] L. Chmurzyński, A. Liwo, A. Wawrzynów, and A. Tempczyk, J. Mol. Struct. 143, 375 (1986).

[18] A. Wawrzynów, A. Liwo, L. Chmurzyński, and A. Tempczyk, J. Mol. Struct. 143, 375 (1986).

[19] E. M. Eveleth, Theor. Chim. Acta 11, 145 (1968)

[20] J. Del Bene and H. H. Jaffé, J. Chem. Phys. 49, 1221 (1968).
[21] S. Kobinata and A. Nagakura, Theoret. Chim. Acta 14, 415 (1969).

[22] Tae-Kyu Ha, Theoret. Chim. Acta 43, 337 (1977).

[23] K. K. Sharma and R. J. Boyd, Theoret. Chim. Acta 57, 163 (1980).

[24] V. Kulkarni, A. Roy, and C. C. Patel, J. Mol. Struct. 71, 253 (1981).

[25] M. Scholz, J. Prakt. Chem. 323, 571 (1981); 324, 85 (1982).

[26] M. Scholz, R. Gotze, G. Kluge, L. Klosnic, and I. Novak, Z. Phys. Chem. (Leipzig) 265, 897 (1981).

[27] H. H. Jaffé and G. Doak, J. Am. Chem. Soc. 77, 4441 (1955).

[28] D. D. Perrin, Dissociation Constants of Organic Bases in Aqueous Solutions, Butterworths, London (1965).

[29] C. Klotufar, F. Krasovec, and M. Kusar, Croat. Chim. Acta 40, 23 (1968).

[30] J. N. Gardner and A. R. Katritzky, J. Chem. Soc. 1957, 4375.

[31] L. Chmurzyński, Ph. D. Thesis, University of Gdańsk, Gdańsk (1986).

[32] A. Wawrzynów, Ph. D. Thesis, University of Gdańsk, Gdańsk (1985).

[33] B. A. Korolev, K. A. Osmolovskaa, and K. M. Dumaev, Zh. Obshch. Khim. 49, 898 (1977).

[34] J. A. Pople and G. A. Segal, J. Chem. Phys. 43, 136 (1965); 44, 3289 (1966).

[35] M. J. S. Dewar and W. Thiel, J. Am. Chem. Soc. 99, 4899 (1977).

[36] K. Wiberg, Tetrahedron 24, 1083 (1968).

[37] G. Tsoukaris, Acta Crystallogr. 14, 914 (1961).

[38] A. Caron, G. J. Palenik, E. Goldish, and J. Donohue, Acta Crystallogr. 17, 102 (1964).

[39] C. Réart, Acta Crystallogr. 13, 63 (1963).

[40] A. R. Katritzky, E. W. Randall, and L. E. Sutton, J. Chem. Soc. 1957, 1769. 